\title{
Physicochemical properties and filling capacity of an experimental iodoform-based paste in primary teeth
}

\author{
Renata Pereira de Samuel \\ MARQUES(a) \\ Cacio MOURA-NETTO(b) ID \\ Natalia Matsuda de OLIVEIRA(a) \\ Carmela Rampazzo BRESOLIN(c) iD \\ Anna Carolina Volpi \\ MELLO-MOURA(b) iD \\ Fausto Medeiros MENDES(a) \\ Tatiane Fernandes NOVAES(d) iD \\ (a) Universidade de São Paulo - USP, School of \\ Dentistry, Department of Pediatric Dentistry, \\ School of Dentistry, São Paulo, SP, Brazil. \\ (b) Universidade Católica Portuguesa, Center \\ for Interdisciplinary Research in Health (CIIS), \\ Faculty of Dental Medicine, Viseu, Portugal. \\ (c)FMU Centro Universitário, School of \\ Dentistry, São Paulo, SP, Brazil. \\ (d) Universidade Cruzeiro do Sul, School of \\ Dentistry, São Paulo, SP, Brazil. \\ Declaration of Interests: The authors \\ certify that they have no commercial or \\ associative interest that represents a conflict \\ of interest in connection with the manuscript.
}

Corresponding Author:

Tatiane Fernandes Novaes

E-mail: tatifn@globo.com

https://doi.org/10.1590/1807-3107bor-2020.vol34.0089

Submitted: January 20, 2020

Accepted for publication: May 28, 2020

Last revision: June 16, 2020

\begin{abstract}
In this study, we evaluated the physicochemical properties (PCP; radiopacity, flow, $\mathrm{pH}$, and solubility) and the quality of root canal filling provided by an experimental industrialized paste (EP), with the same active ingredients as those of the Guedes Pinto paste, compared with the Vitapex ${ }^{\circledR}$ paste. PCP were analyzed according to the ANSI/ADA laboratory testing methods for endodontic filling and sealing materials. To analyze filling capacity, 120 artificial primary teeth (60 maxillary incisors [MIs] and 60 mandibulary molars [MMs]) were endodontically treated. The teeth were divided into eight groups based on the dental group (MIs or MMs), filling material (Vitapex ${ }^{\circledR}$ or $\mathrm{EP})$, and insertion method (syringe or lentulo). The Image $\mathrm{J}^{\circledR}$ software was used to analyze the initial an final digital radiographies of each tooth, measuring and comparing root canal and void areas. The percentage of filling failure areas was obtained. Data were submitted to ANOVA and Tukey test of mean comparison. Regarding PCP, both pastes presented results according the ANSI/ADA standards. Flow capacity: Vitapex: $19.6 \mathrm{~mm}$, EP: $25 \mathrm{~mm}$ ( $\mathrm{p}<0.01$ ); radiopacity: Vitapex: $4.47 \mathrm{mmAl}$, EP: $6.06 \mathrm{mmAl}$ ( $\mathrm{p}<0.01$ ); $\mathrm{pH}$ after 28 days: Vitapex: 7.79, EP: 8.19 ( $p=0.12$ ); and solubility after 28 days: Vitapex: $2.68 \%$, EP: $2.89 \%$ ( $p>0.05$ ). Regarding filling capacity analysis, EP demonstrated $12.5 \%$ of failure against $31.5 \%$ of Vitapex ( $p<0.01$ ). Compared to Vitapex, EP presented statistically significantly better results in flow, radiopacity, $\mathrm{pH}$, and filling capacity. Molars presented more filling failures than incisors. The insertion method using a syringe and a thin tip was significantly better than that using Lentulo spiral carriers.
\end{abstract}

Keywords: Tooth, Deciduous; Endodontics; Root Canal Obturation.

\section{Introduction}

Endodontic treatment of primary teeth is a frequent clinical procedure in pediatric dentistry. The treatment is usually performed for dental caries (still considered a public health problem worldwide) or dental trauma, which is common in young children., ${ }^{1,2}$

Endodontic treatment success is often dependent on several factors, ranging from dental preoperatory conditions to the choice of final tooth restoration. Among these factors, the importance of the choice of endodontic filling material cannot be overlooked. 
For treatment of primary teeth, endodontic filling materials must meet certain basic requirements, such as biocompatibility to peri-radicular tissues, slow resorption (to follow primary teeth physiological resorption), antimicrobial characteristics, and physicochemical properties, including radiopacity and flow. ${ }^{3,4,5,6}$ Moreover, the success of endodontic treatment of deciduous teeth depends on the quality of root canal filling, which is expected to present a complete fill of the root canal system without extrusion to the periapical tissues. ${ }^{78}$ Among different options used globally, Vitape ${ }^{\circledR}$ (Neo International, Federal Way, USA), a premix of calcium hydroxide and iodoform, is considered the gold standard in filling materials for primary teeth, with considerable success rates. Among other features for being an excellent endodontic filling material, Vitape ${ }^{\circledR}$ can induce bone formation. Using syringes with extremely thin plastic injection tips, the surgeon can easily dispose the paste into more apical portions of root canals, providing a compact seal and great filling., ${ }^{9,10,11}$ However, the major concern for using Vitapex is that it is not commercialized in South America and other third-world countries.

In Brazil, the most commonly used root canal filling material for primary teeth is Guedes Pinto paste, which is composed of iodoform, prednisolone acetate, rifamycin sodium, and camphorated paramonochlorophenol (PMCC). ${ }^{12,13,14,15}$ Previous studies have demonstrated good antimicrobial and biocompatibility characteristics of the paste; clinical studies have also demonstrated positive results with the use of Guedes Pinto. Although the paste meets several requirements to be considered an appropriate endodontic filling material for primary teeth, limitations to its use include the need to be manipulated right before its use and difficulties related to its insertion in the root canal. ${ }^{13,16,17,18}$

To overcome these challenges, an experimental formulation based on the original formula of Guedes Pinto paste was developed (Registered Patent PI0802256-9, INPI 2018). The new formulation contains the same active components (iodoform, prednisolone acetate, rifamycin sodium, and PMCC) but with addition of new excipients. This experimental paste is presented in ready-to-use plastic syringes with thin plastic injection tips.
Considering the experimental nature of the product, strong scientific evidence must be built for its physicochemical properties and quality of root canal filling. Therefore, in this study, we conducted physicochemical tests for this experimental paste and compared the obtained results with those obtained following the use of Vitapex ${ }^{\circledast}$ paste.

\section{Methodology}

A previously trained operator conducted the study evaluating the physicochemical properties of flow, radiopacity, $\mathrm{pH}$ and solubility, and the quality of root canal filling of both pastes by using two different insertion techniques.

Vitape ${ }^{\circledR}$ and the experimental paste were used in the present study. Both pastes were presented in identical ready-to-use plastic syringes with a considerably long and thin insertion point. To blind the pastes to the operator, these syringes were named paste $A$ and paste $B$, respectively. The physicochemical properties were tested according to the American National Standards Institute/American Dental Association ANSI/ADA 57-2000 specification for endodontic sealing materials, ${ }^{19}$ which recommends that the trials must be performed at room temperature of $23^{\circ} \mathrm{C} \pm 2{ }^{\circ} \mathrm{C} .{ }^{20}$

\section{Flow}

Each $0.5 \mathrm{~mL}$ of paste $A$ and paste $B$ were placed in the center of a glass plate. After $3 \mathrm{~min}$, another glass plate was placed on the top of the first one, directly over the paste applying a total weight of $120 \mathrm{mg}$, resulting in compression. The set was let to remain stable for $10 \mathrm{~min}$, after which the smallest and the largest diameters of each specimen were measured using a ruler graduated in millimeters. The mean of the diameters (in $\mathrm{mm}$ ) was established for each paste. The test was repeated five times. The ANSI/ADA standards recommend the flow requirement not to be less than $17 \mathrm{~mm}$.

\section{Radiopacity}

In total, 10 stainless steel ring molds (diameter: $10 \pm 0.1 \mathrm{~mm}$; height, $1 \pm 0.1 \mathrm{~mm}$ ) were used. The rings were placed over a thin glass plate and filled with 
either paste A or paste B. A small sheet of polyester film was placed over the rings to ensure the paste thickness of $1 \mathrm{~mm}$. To classify the radiopacity, a $98 \%$ pure aluminum step wedge was used. After filling the molds, a digital $x$-ray device and a digital sensor (Diox and Fit ${ }^{\circledR}$, MicroImagem, Indaiatuba, Brazil) were used to obtain digital radiographs of each specimen next to the aluminum scale. The distance and radiation time were the same for each specimen ( $3 \mathrm{~cm}$ and $0.04 \mathrm{~s}$, respectively).

The images were analyzed using the Image ${ }^{\circledR}$ software (University of Madison, Madison, USA). The histogram value in gray scale corresponding to $7 \mathrm{~mm}$ of aluminum was considered as reference to calibrate the gray values. Three measurements were obtained for each specimen, using an area of $20 \times 20$ pixels for the image of the aluminum scale and for the image of the paste at three different spots inside the ring. The test was repeated ten times.

The mean gray value for each sample was calculated and converted to millimeters of aluminum (mmAl), by using the correspondent gray value to $7 \mathrm{~mm}$ in the aluminum scale. The ANSI/ADA standards recommend radiopacity not less than $3 \mathrm{~mm}$ of aluminum.

\section{Filling capacity}

A total of 120 artificial deciduous teeth (Denarte ${ }^{\circledast} /$ IM do Brazil, São Paulo, Brazil) were used in the study: 60 maxillary central incisors and 60 maxillary first molars. Manufactured using synthetic resins, the teeth have the external and internal anatomy of deciduous teeth, beholding an endodontic cavity filled with red wax that simulates the pulp tissue. The use of this artificial teeth was validated in a previous study. ${ }^{21}$ The teeth were distributed in four groups as follows: Group 1: 30 central incisors filled with the experimental paste; Group 2: 30 central incisors filled with the Vitapex paste; Group 3: 30 molars filled with the experimental paste; Group 4: 30 molars filled with the Vitapex paste.

\section{Endodontic treatment}

To analyze the existence of voids or obstructions in the canals, initial digital images of all the 120 teeth were obtained using digital radiographs. If case of an irregularity, the sample was replaced with a new one. The images were standardized by placing the teeth in an epoxy resin mold and using the same distance and radiation time for all teeth $(3 \mathrm{~cm}$ and $0.04 \mathrm{~s}$, respectively).

A trained operator completed all the 120 endodontic treatments, in accordance with an operatory protocol: endodontic access using a high-speed 1014HL round bur, complemented with Endo-Z bur (Dentsply Maillefer, Ballaigues, Switzerland). The working length was established by introducing a \#10 K file into the root canal until the tip was visualized at the apical foramen. Thus, it was set as $14 \mathrm{~mm}$ to the incisors, $14 \mathrm{~mm}$ to the palatine root, and $13 \mathrm{~mm}$ to both vestibular roots of the molars. Endodontic preparation was performed using a manual crown-down technique with $2.5 \%$ sodium hypochlorite as an irrigant solution and light Endo-PTC as a lubricant (Farmácia Fórmula e Ação, São Paulo, Brazil). The apical preparation was set to a \#35 K file for incisors. For molars, \#30 K-Flex file on buccal canals and \#40 K-Flex file for palatine canals. Final irrigation was performed using $2.5 \%$ sodium hypochlorite, followed by $17 \%$ EDTA-T (Farmácia Fórmula e Ação). Irrigation was performed using 30G Navitips (Ultradent, South Jordan, USA). Subsequently, the root canals were dried using the capillary tips (Ultradent) and paper points (Dentsply) before obturation.

\section{Root canal filling}

Paste $A$ and paste $B$ were filled in identical plastic syringes named PASTE A and PASTE $B$ to blind the operator of the treatment. The teeth were divided into two subgroups on the basis of paste insertion method: syringe and tip or lentulo spiral carrier.

Syringe sub-groups: Vitapex insertion tip, which was used for both paste A and paste B, is thin and flexible, allowing for a good insertion into root canals. The operator introduced the tip carefully inside the root canal until $3 \mathrm{~mm}$ prior to the working length. Next, the material was placed inside the canal, removing the tip until the canal was fully filled. The excess material in the pulp chamber was then cleaned using a cotton pellet. A final digital 
radiograph was taken in the same conditions as those for the initial radiograph.

Lentulo spiral groups: Paste A and paste B were inserted in the same manner as were done in the syringe sub-groups. After canal filling, a \#25 lentulo spiral carrier was placed $3 \mathrm{~mm}$ prior to the working length and activated for $3 \mathrm{~s}$. Next, it was slowly removed. The excess material in the pulp chamber was then cleaned with a cotton pellet. A final digital radiograph was taken in the same conditions as those for the initial radiograph.

\section{Digital radiography evaluation}

The Image $\mathrm{J}^{\circledR}$ 1.53a software (Wayne Rasband, $\mathrm{NIH}$, USA) was used for image analysis. Using the final radiograph, we measured the total area $\left(\mathrm{mm}^{2}\right)$ of the root canal. Next, all area of voids or failure in the filling were individually measured. The percentage of failure areas were then calculated.

\section{$\mathrm{pH}$ and solubility}

After filling capacity test, 10 incisors from each paste group were randomly selected for $\mathrm{pH}$ and solubility tests. Pulp chambers were sealed with sticky wax and the teeth were weighed in a precision balance (Mettler Toledo LCC, Columbus, OH, USA). Next, they were individually immersed in a plastic tube containing $10 \mathrm{~mL}$ of deionized water. After time intervals of $30 \mathrm{~min}, 2 \mathrm{~h}$, and 1, 7, 14, and 28 days, the teeth were removed, weighed, and immersed into a new plastic tube containing an equal volume of fresh deionized water. The $\mathrm{pH}$ in the solutions was analyzed using a $\mathrm{pH}$ meter (Mettler Toledo LCC).

\section{Statistical analysis}

The level of significance was set at $5 \%$, and all the analyses were performed using the Stata 13.0 software (Stata Corp, College Station, TX,
USA). Normal distribution was verified by using the Kolmogorov-Smirnov test (with Lilliefors correction). One-way ANOVA was used for physicochemical tests, complemented by Tukey post-hoc test. For statistical analysis of filling capacity, three-way ANOVA was used, complemented by Tukey ad-hoc test.

\section{Results}

\section{Flow test}

Both paste A and paste B presented results in line with the ADA standard $\mathrm{n}^{\circ} 57$ (not $<17 \mathrm{~mm}$ ). Experimental paste presented a significantly higher flow than Vitapex ${ }^{\circledR}$ paste (Table).

\section{Radiopacity test}

Both paste A and paste B presented values higher than the minimum stipulated to endodontic filling materials according to the ADA standard $n^{\circ} 57^{19}$, which is $3 \mathrm{~mm}$ Al. Experimental paste presented a significantly higher level of radiopacity than Vitapex ${ }^{\circledR}$ paste (Table).

\section{pH}

On comparing all time intervals, we found no significant differences for each of the paste. Comparing the pastes, the experimental paste presented a significantly higher $\mathrm{pH}$ than Vitapex ${ }^{\circledR}$ (Table).

\section{Solubility}

On comparing all time intervals, we found no significant differences for each of the paste. The final period values (28 days) are presented in Table.

Regarding filling capacity, the voids and failure percentages of all the groups are presented in Figure. On comparing the pastes for each variable (such as tooth type and the insertion method), the experimental

Table. Means and standard deviations of radiopacity, flow, $\mathrm{pH}$, and solubility.

\begin{tabular}{lcccc}
\hline Variable & Radiopacity $(\mathrm{mm} \mathrm{Al})$ & Flow $(\mathrm{mm})$ & $\mathrm{pH}(28$ days) & Solubility 28 days $(\%)$ \\
\hline Vitapex $^{\circledR}$ & $4.47 \pm 0.29$ & $19.6 \pm 0.42$ & $7.79 \pm 0.17$ & 2.68 \\
Experimental & $6.06 \pm 0.49$ & $25.0 \pm 0.61$ & $8.19 \pm 0.18$ & 2.89 \\
ANOVA - Tukey test & $\mathrm{p}<0.01$ & $\mathrm{p}<0.01$ & $\mathrm{p}=0.012$ & n.s. \\
\hline
\end{tabular}

n.s.: not significant. 


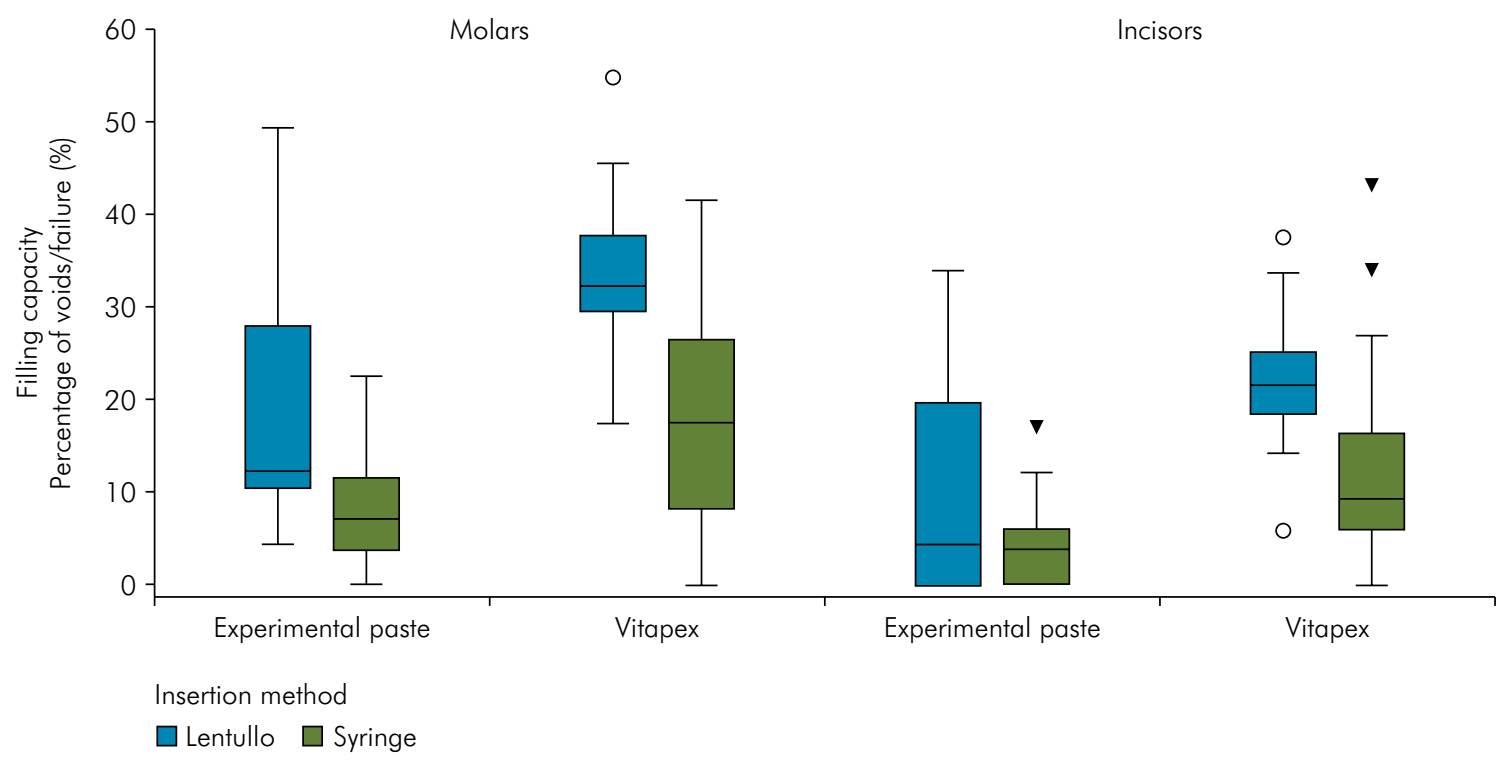

Figure. Regarding filling capacity, the voids and failure percentages of all groups.

paste presented a significantly lower percentage of failure than Vitapex $(\mathrm{p}<0.01)$. Three-way ANOVA demonstrated no significant differences between the interaction of variables (paste $X$ tooth $X$ insertion method: $\mathrm{p}=0.92$ ).

\section{Discussion}

Endodontic treatment of deciduous teeth continues to be a highly relevant dental procedure in pediatric dentistry. ${ }^{22}$ The search for a perfect filling material encouraged us to investigate a new root canal filling material. Vitapex ${ }^{\circledast}$ paste is considered the gold standard in literature. ${ }^{23,24,25,26,27,28}$ However, in Brazil, Vitapexis not commercialized and therefore Guedes-Pinto paste, also an iodoform-based preparation, is considered a good alternative. However, Guedes-Pinto paste has always been associated with handling difficulties for need of immediate manipulation..$^{13}$ Therefore, a new ready-to-use formulation presented in injection syringes and composed of the same active components was idealized. In this study, we investigated the physicochemical characteristics and quality of root canal filling of this new formulation.

Both paste $A$ and paste $B$ presented radiopacity and flow values in accordance with the ADA standard of $n^{\circ} 57 .{ }^{19}$ Nevertheless, the experimental paste demonstrated significantly better results in radiopacity. Considering that iodoform is the component responsible for radiopacity in both pastes, ${ }^{29}$ we believe that the greater proportion of iodoform in the experimental paste may justify its superiority in radiopacity results. Iodoform constitutes $69.2 \%$ of the experimental paste's formulation, ${ }^{14}$ whereas it constitutes only $40.4 \%$ of Vitapex ${ }^{\circledast}$ formulation, per manufacturer's information (NeoDental Chemical Products Co, Tokyo, Japan). Although higher paste radiopacity has the advantage of allowing for better visualization in the radiograph, even in smaller amounts, it can mask some filling failure. To ensure this phenomenon does not occur in our sample, we performed an additional radiograph for each tooth in a proximal view and if any failure was presented only in this second view, the percentage was also recorded. In our study, none of the samples presented this condition.

Regarding flow capacity, we believe the difference between the percentages of liquid components of the pastes may have influenced the results. The experimental paste comprised PMCC as a liquid component of the composition and uses Rifocort in the proportion of $23.8 \%$, which contains polyethylene glycol as vehicle. Vitapex ${ }^{\circledast}$ has a lower proportion of 
the vehicle $(22 \%)$ and also the presence of calcium hydroxide, which is often used to decrease flow in many endodontic filling materials. ${ }^{3}$ Furthermore, the vehicle used in Vitapex is silicone oil. Oil vehicles offer aggregating properties and hinder solubilization. ${ }^{30}$ On the contrary, the polyethylene glycol vehicle used in the experimental paste is a viscous water-soluble vehicle with better dissociative properties, which may also justify its better results in flow capacity. ${ }^{31}$ Although both pastes met the ANSI/ADA recommendations, it is known that a higher flow paste would promote a higher filling capacity. This theory is in agreement with filling capacity results presented in our study. The $\mathrm{pH}$ and solubility of both pastes did not demonstrate significant differences at all time periods evaluated. The $\mathrm{pH}$ ranged between 7.6 and 8.4 and solubility at 28 days did not achieve $3 \%$ for both pastes.

The dental group of molars presented the highest percentage of failure in filling capacity. We believe that anatomical peculiarities of each dental group contributed greatly to this result. The internal anatomy of root canals may be considered a reflection of the external anatomy of the root. Thus, central incisor canals are generally straighter, and circular, presenting lesser difficulties during not only cleaning and shaping but also obturation. The opposite can be observed in the group of molars, whose root curvatures and flattening areas are reflected in narrower channels, para-apical exits, and other details that often complicate those steps of endodontic treatment. ${ }^{32,33,34}$

Certain details of the adopted methodology should be considered, such as the use of artificial primary teeth made of resin. Although these work models represent an advance in laboratory endodontics, ${ }^{13}$ they may not perfectly reproduce the natural teeth. In addition, the wax that fills the endodontic canal of the artificial primary teeth is difficult to remove and may have altered, in some cases, the establishment of working length and filling quality. Some artificial teeth also offered difficulties accessing the root apex, presenting lateral exits, obstructions, and voids in areas near the root canal.

While evaluating the quality of filling provided by the examined pastes, we must consider that this is an in vitro study, and in some aspects, this might have favored the results. For example, there were no clinical difficulties such as mouth opening limitations, need for psychological conditioning, or other possible complications that may often occur during pediatric treatment.

Vitape ${ }^{\circledast}$ presented an inferior general result in filling quality when compared with the experimental paste. We observed higher failure rates with Vitapex ${ }^{\circledR}$ use in both the tested dental groups (incisors and molars) and insertion methods (syringe or lentulo). This finding could be attributed to the different formulation of the pastes and their physicochemical properties. Considering that the experimental paste presented better flow capacity than Vitapex, it seems that the experimental paste presented better filling quality. However, the obturation of all dental groups was performed in the same date and in sequence, which may have involved operator fatigue. Random distribution of teeth and type of material are indicated in the performance of other works to overcome this present limitation.

In contrast to our results, Asokan et al., ${ }^{35}$ using computerized tomography, compared the percentage of the filled area volume provided by three endodontic pastes. Vitapex ${ }^{\circledast}$ paste presented superior results ( $95 \%$ filling of the total root canal volume), compared to an iodoform-based paste, Metapex (88\%), and a zinc oxide-based paste (84\%). Notably, these studies compared Vitapex ${ }^{\circledR}$ with zinc oxide-based pastes. ${ }^{19,31,36,37}$ In the present study, the comparison was stablished between Vitapex ${ }^{\circledR}$ and the experimental paste, which does not comprise zinc oxide or eugenol in its formulation, making it difficult to compare our results with those of earlier studies.

\section{Conclusion}

The results for both paste A and paste $B$ were in accordance with the ADA standards. The experimental paste presented significant better flow, radiopacity, $\mathrm{pH}$, and filling quality than Vitapex ${ }^{\circledR}$. Molars presented more filling failures than incisors. The insertion method using syringe and a thin tip was significantly better than the use of Lentulo spiral carriers. 


\section{References}

1. Costa VP, Goettems ML, Baldissera EZ, Bertoldi AD, Torriani DD. Clinical and radiographic sequelae to primary teeth affected by dental trauma: a 9-year retrospective study. Braz Oral Res. 2016 Aug;30(1):89. https://doi.org/10.1590/1807-3107BOR-2016.vol30.0089

2. Xia X, Man Z, Jin H, Du R, Sun W, Wang X. Vitapex can promote the expression of BMP-2 during the bone regeneration of periapical lesions in rats. J Indian Soc Pedod Prev Dent. 2013 Oct-Dec;31(4):249-53. https://doi.org/10.4103/0970-4388.121825

3. Asokan S, Sooriaprakas C, Raghu V, Bairavi R. Volumetric analysis of root canal fillings in primary teeth using spiral computed tomography: an in vitro study. J Dent Child (Chic). 2012 May-Aug;79(2):46-8.

4. Cerqueira DF, Mello-Moura AC, Santos EM, Guedes-Pinto AC. Cytotoxicity, histopathological, microbiological and clinical aspects of an endodontic iodoform-based paste used in pediatric dentistry: a review. J Clin Pediatr Dent. 2008;32(2):105-10. https://doi.org/10.17796/icpd.32.2.k1wx5571h2w85430

5. Mello-Moura AC, Fanaro J, Nicoletti MA, Mendes FM, Wanderley MT, Guedes-Pinto AC. Variability in the proportion of components of iodoform-based Guedes-Pinto paste mixed by dental students and pediatric dentists. Indian J Dent Res. 2011 Nov-Dec;22(6):781-5. https://doi.org/10.4103/0970-9290.94668

6. Barja-Fidalgo F, Moutinho-Ribeiro M, Oliveira MA, Oliveira BH. A systematic review of root canal filling materials for deciduous teeth: is there an alternative for zinc oxide-eugenol? ISRN Dent. 2011;2011:367318. https://doi.org/10.5402/2011/367318

7. Amorim LF, Toledo OA, Estrela CR, Decurcio DA, Estrela C. Antimicrobial analysis of different root canal filling pastes used in pediatric dentistry by two experimental methods. Braz Dent J. 2006;17(4):317-22. https://doi.org/10.1590/S0103-64402006000400010

8. Bawazir OA, Salama FS. Clinical evaluation of root canal obturation methods in primary teeth. Pediatr Dent. 2006 Jan-Feb;28(1):39-47.

9. Deonízio MD, Sydney GB, Batista A, Estrela C. Root canal filling with calcium hydroxide paste using lentullo spiral at different speeds.

Dent Press Endod. 2011 Apr-Jun;1(1):58-63. https://doi.org/10.14436/2178-3713.1.1.058-063.oar

10. Hiremath MC, Srivastava P. Comparative evaluation of endodontic pressure syringe, insulin syringe, jiffy tube, and local anesthetic syringe in obturation of primary teeth: an in vitro study. J Nat Sci Biol Med. 2016 Jul-Dec;7(2):130-5. https://doi.org/10.4103/0976-9668.184698

11. American Dental Association. ANSI/ADA Standard No. 57 - Endodontic sealing material: 2000 (reaffirmed 2012). [cited 2017 Feb 04]. Avaiable from: http://www.ada.org/en/science-research/dental-standards/dental-products/products-standards-technical-specificationsand-technical-reports

12. Corrêa-Faria P, Paixão-Gonçalves S, Paiva SM, Pordeus IA. Incidence of dental caries in primary dentition and risk factors: a longitudinal study. Braz Oral Res. 2016 May;30(1):59. https://doi.org/10.1590/1807-3107BOR-2016.vol30.0059

13. American Dental Association. Laboratory testing methods. Endodontic filling and sealing materials. Professional Product Review. 2008;3:(4) [cited 2017 Jan 30]. Avaiable from: http://www.ada.org/goto/ppr

14. Mello-Moura AC, Bresolin CR, Moura-Netto C, Ito A, Araki AT, Imparato JC, et al. Use of artificial primary teeth for endodontic laboratory research: experiments related to canal length determination. BMC Oral Health. 2017 Nov;17(1):131. https://doi.org/10.1186/s12903-017-0420-3

15. Brosnan MG, Natarajan AK, Campbell JM, Drummond BK. Management of the pulp in primary teeth—an update. N Z Dent J. 2014 Dec;110(4):119-23.

16. Antoniazzi BF, Pires CW, Bresolin CR, Weiss RN, Praetzel JR. Antimicrobial activity of different filling pastes for deciduous tooth treatment. Braz Oral Res. 2015;29(1):1-6. https://doi.org/10.1590/1807-3107BOR-2015.vol29.0005

17. Al-Ostwani AO, Al-Monaqel BM, Al-Tinawi MK. A clinical and radiographic study of four different root canal fillings in primary molars. J Indian Soc Pedod Prev Dent. 2016 Jan-Mar;34(1):55-9. https://doi.org/10.4103/0970-4388.175515

18. Silva LA, Leonardo MR, Oliveira DS, Silva RA, Queiroz AM, Hernández PG, et al. Histopathological evaluation of root canal filling materials for primary teeth. Braz Dent J. 2010 Jan;21(1):38-45. https://doi.org/10.1590/S0103-64402010000100006

19. Mortazavi M, Mesbahi M. Comparison of zinc oxide and eugenol, and Vitapex for root canal treatment of necrotic primary teeth. Int J Paediatr Dent. 2004 Nov; 14(6):417-24. https://doi.org/10.1111/j.1365-263X.2004.00544.x

20. Imamura Y, Tanaka Y, Nagai A, Yamashita K, Takagi Y. Self-sealing ability of OCP-mediated cement as a deciduous root canal filling materia. Dent Mater J. 2010 Oct;29(5):582-8. https://doi.org/10.4012/dmj.2010-001

21. Pinto DN, Sousa DL, Araújo RB, Moreira-Neto JJ. Eighteen-month clinical and radiographic evaluation of two root canal-filling materials in primary teeth with pulp necrosis secondary to trauma. Dent Traumatol. 2011 Jun;27(3):221-4. https://doi.org/10.1111/j.1600-9657.2011.00978.x

22. Ordinola-Zapata R, Bramante CM, García-Godoy F, Moldaver BI, Gagliardi Minotti P, Tercília Grizzo L, et al. The effect of radiopacifiers agents on $\mathrm{pH}$, calcium release, radiopacity, and antimicrobial properties of different calcium hydroxide dressings. Microsc Res Tech. 2015 Jul;78(7):620-5. https://doi.org/10.1002/jemt.22521 
23. Carvalho-Junior JR, Correr-Sobrinho L, Correr AB, Sinhoreti MA, Consani S, Sousa-Neto MD. Solubility and dimensional change after setting of root canal sealers: a proposal for smaller dimensions of test samples. J Endod. 2007 Sep;33(9):1110-6. https://doi.org/10.1016/i.joen.2007.06.004

24. Kuga MC, Faria G, Só MV, Keine KC, Santos AD, Duarte MA, et al. The impact of the addition of iodoform on the physicochemical properties of an epoxy-based endodontic sealer. J Appl Oral Sci. 2014 Apr;22(2):125-30. https://doi.org/10.1590/1678-775720130052

25. Fava LR, Saunders WP. Calcium hydroxide pastes: classification and clinical indications. Int Endod J. 1999 Aug;32(4):257-82. https://doi.org/10.1046/j.1365-2591.1999.00232.x

26. Nunes AC, Rocha MJ. Hydroxyl and calcium ions diffusion from endodontic materials through roots of primary teeth - in vitro study. $J$ Appl Oral Sci. 2005 Jun;13(2):187-92. https://doi.org/10.1590/S1678-77572005000200018

27. Bagherian A, Kalhori KA, Sadeghi M, Mirhosseini F, Parisay I. An in vitro study of root and canal morphology of human deciduous molars in an Iranian population. J Oral Sci. 2010 Sep;52(3):397-403. https://doi.org/10.2334/josnusd.52.397

28. Kurthukoti AJ, Sharma P, Swamy DF, Shashidara R, Swamy EB. Computed Tomographic Morphometry of the Internal Anatomy of Mandibular Second Primary Molars. Int J Clin Pediatr Dent. 2015 Sep-Dec;8(3):202-7. https://doi.org/10.5005/ip-journals-10005-1313

29. Gaurav V, Srivastava N, Rana V, Adlakha VK. A study of root canal morphology of human primary incisors and molars using cone beam computerized tomography: an in vitro study. J Indian Soc Pedod Prev Dent. 2013 Oct-Dec;31(4):254-9. https://doi.org/10.4103/0970-4388.121827

30. Pramila R, Muthu MS, Deepa G, Farzan JM, Rodrigues SJ. Pulpectomies in primary mandibular molars: a comparison of outcomes using three root filling materials. Int Endod J. 2016 May;49(5):413-21. https://doi.org/10.1111/iej.12478

31. Trairatvorakul C, Chunlasikaiwan S. Success of pulpectomy with zinc oxide-eugenol vs calcium hydroxide/iodoform paste in primary molars: a clinical study. Pediatr Dent. 2008 Jul-Aug;30(4):303-8.

32. Huang TH, Ding SJ, Kao CT. Biocompatibility of various formula root filling materials for primary teeth. J Biomed Mater Res B Appl Biomater. 2007 Feb;80(2):486-90. https://doi.org/10.1002/jbm.b.30621

33. Almeida JF, Gomes BP, Ferraz CC, Souza-Filho FJ, Zaia AA. Filling of artificial lateral canals and microleakage and flow of five endodontic sealers. Int Endod J. 2007 Sep;40(9):692-9. https://doi.org/10.1111/j.1365-2591.2007.01268.x

34. Schäfer E, Zandbiglari T. Solubility of root-canal sealers in water and artificial saliva. Int Endod J. 2003 Oct;36(10):660-9. https://doi.org/10.1046/i.1365-2591.2003.00705.x

35. McMichen FR, Pearson G, Rahbaran S, Gulabivala K. A comparative study of selected physical properties of five root-canal sealers. Int Endod J. 2003 Sep;36(9):629-35. https://doi.org/10.1046/j.1365-2591.2003.00701.x

36. Sarin A, Gupta P, Sachdeva J, Gupta A, Sachdeva S, Nagpal R. Effect of Different Obturation Techniques on the Prognosis of Endodontic Therapy: A Retrospective Comparative Analysis. J Contemp Dent Pract. 2016 Jul;17(7):582-6. https://doi.org/10.5005/ip-journals-10024-1893

37. Ng YL, Mann V, Rahbaran S, Lewsey J, Gulabivala K. Outcome of primary root canal treatment: systematic review of the literature Part 2. Influence of clinical factors. Int Endod J. 2008 Jan;41(1):6-31. 